\title{
Teaching with MATLAB Simulation in the Power Electronics Technology Course
}

\author{
Zhou Miaolei \\ College of Communication and Engineering \\ Jilin University \\ Changchun, China \\ zml@jlu.edu.cn
}

\author{
Zhao Yu \\ College of Communication and Engineering \\ Jilin University \\ Changchun, China \\ zhaoyu13@jlu.edu.cn
}

\begin{abstract}
The Power Electronics Technology course is a professional basic course of Electrical Engineering and Automation, in which complex circuit structure and complicated working procedure of converter technology bring difficulties into teaching process. In this paper, by taking PWM inverse circuit as an example, a teaching mode is introduced with MATLAB simulation tool. By the application of this mode, a circuit simulation model is built. As a consequence, the simulation graphs are obtained and the problems appearing in the experiment are analyzed easily. It is shown in the comparison test of teaching effect that students can quickly comprehend the theoretical knowledge about circuits by using the simulation tool. So the teaching goal is achieved well because the problems of the traditional teaching mode are overcome.
\end{abstract}

Keywords- Power Electronics Technology; PWM; MATLAB; Teaching Mode; Comparison Test

\section{INTRODUCTION}

Power Electronics Technology [1, 2] becomes an emerging technology containing electricity, electronics and control theory, and it is a compulsory course of the major of Electrical Engineering and Automation. Differing from Information Electronic Technology mainly processing information, Power Electronics Technology focuses on Power Conversion that the range of power is from hundreds of MW even GW to a few W [3, 4]. As one of the important contents of the course, Power Electronic Converter Technology about all kinds of converter devices includes electromagnetic process, basic principle, control method, design calculation and its technical and economic indicators $[5,6]$. It is the basic goal that students should be familiar with the methods to adjust converter devices. Therefore, experimental lesson is an effective way for students to understand and consolidate theory knowledge deeply. They need to link the devices together and record the experiment data and graphs. However, in most universities, the devices are packaged so that it is difficult for students to see the internal structure. They take experiments only by the experiment reference books, and if the result does not meet the requirement, most of students can hardly find the causes and solutions in few minutes.

In order to solve this problem, computer simulation technology based on MATLAB [7-11] is introduced into traditional teaching mode. Students can observe the performance of simulation circuits and achieve graphs by adjusting structures and parameters of the circuits. In this way, rigid line-experiment becomes vivid and concrete so that students' abilities to analyze and solve problems are improved.

\section{Simulation Teaching CASE}

Nowadays, most of the applied inverse circuits are PWM type, which proves the important status of PWM control technology in Power Electronics Technology. So PWM inverse circuit becomes a vital knowledge point in this course. In PWM control mode, switching devices of inverse circuit is taken on-off control, resulting in a series of pulses. By pulse width modulation, the desired equivalent waveform will be achieved, its shape and amplitude included.

\section{A. Main Circuit}

A single-phase bridge inverse main circuit based on full-controlled type IGBT as power device (Fig. 1) is taken as an example in teaching process.

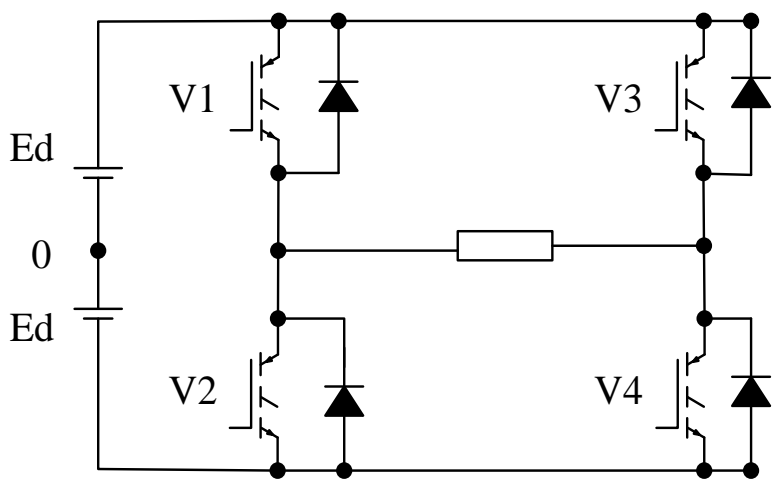

Figure 1. Single-Phase Bridge Inverse Main Circuit.

When this circuit works, the on-off state of V1, V2 and V3, V4 is complementary respectively. Changing the alternating break over time can control and modulate frequency, and meanwhile the voltage amplitude control is actualized by changing the ratio of on-off time. In teaching process, therefore, the changes of voltage and current in the four kinds of on-off state should be the emphasis when analyzing the working process of the circuit. It is also considered that the load current lags behind the voltage if the load is resistance-inductance. In addition, the concept 
of the modulation signal and carrier should be introduced when signals are modulated. To sum up, the knowledge points in this part are so abstract complex that it is hard for students to understand clearly from books, which brings so much trouble for teaching.
Therefore, a simulation teaching mode is proposed to assist traditional experiment, in which students can recognize the working process of the inverse circuits by adjusting parameters of each device. A simulation model based on PWM inverter is shown in Fig. 2.

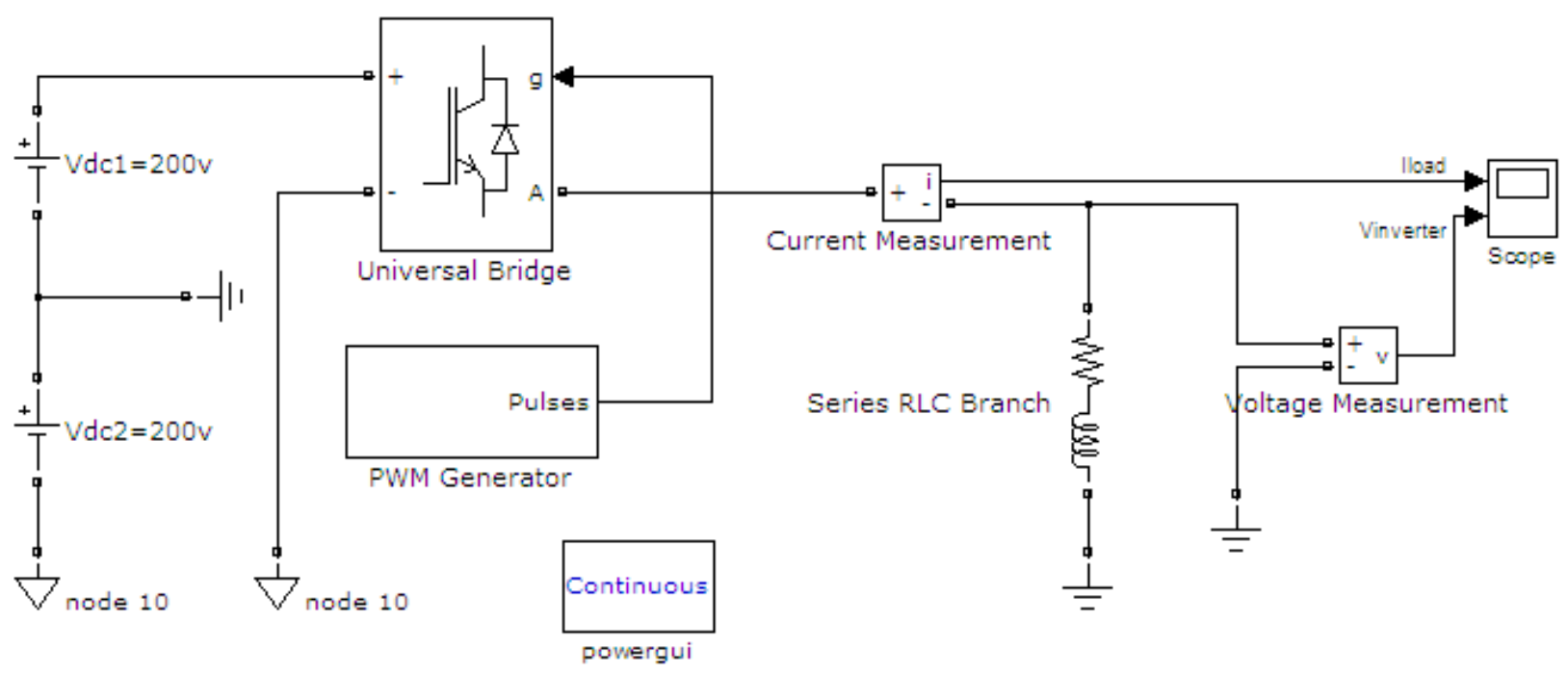

Figure 2. Simulation Model based on PWM Inverter.

\section{B. PWM GENERATOR MODULE}

PWM generator is the core of the PWM inverter control part, which is simulated by the PWM Generator module in Control Blocks in the Matlab Sim Power Systems toolbox sub library named Extras Library. There is an input terminal and an output terminal in this module.

Wherein: Signal(s) terminal is an input terminal of the modulation signal, and Pulse(s) terminal is the output terminal of PWM pulse. It can be customized to produce 2, 4, 6 or 12 pulses. Parameters are set as Fig. 3

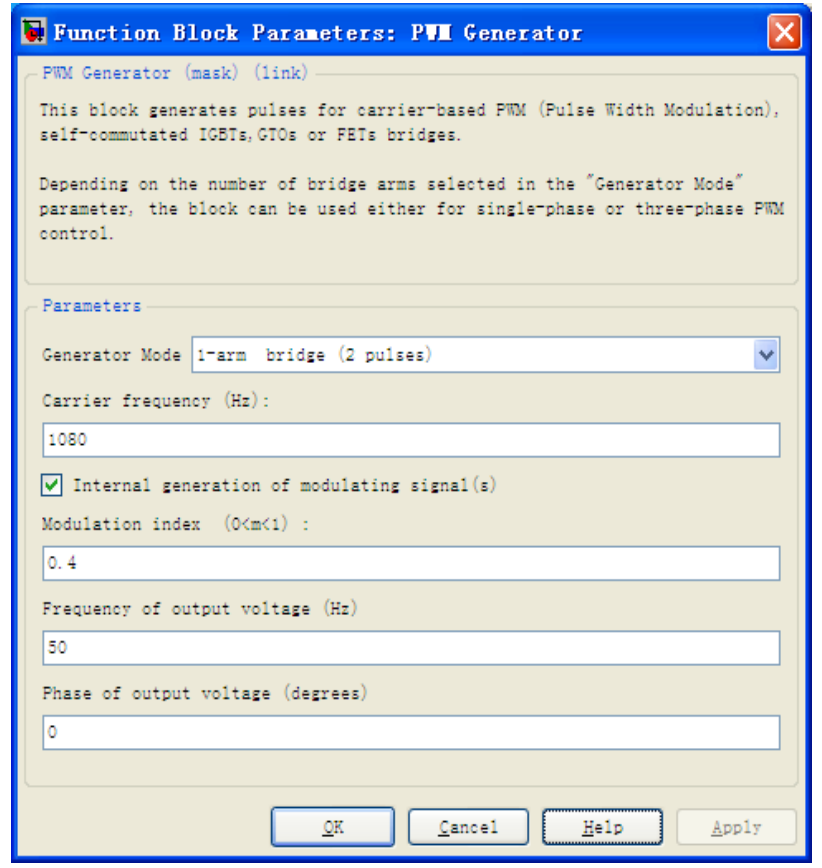

Figure 3. Parameter Settings of PWM Generator Module.

\section{INVERTER MODULE}

Inverter module is achieved by the Universal Bridge module in the Matlab SimPowerSystems toolbox, where the number of bridge arms is chose 1 to make up the single-phase bridge inverse main circuit. Other parameter settings are shown in Fig. 4.

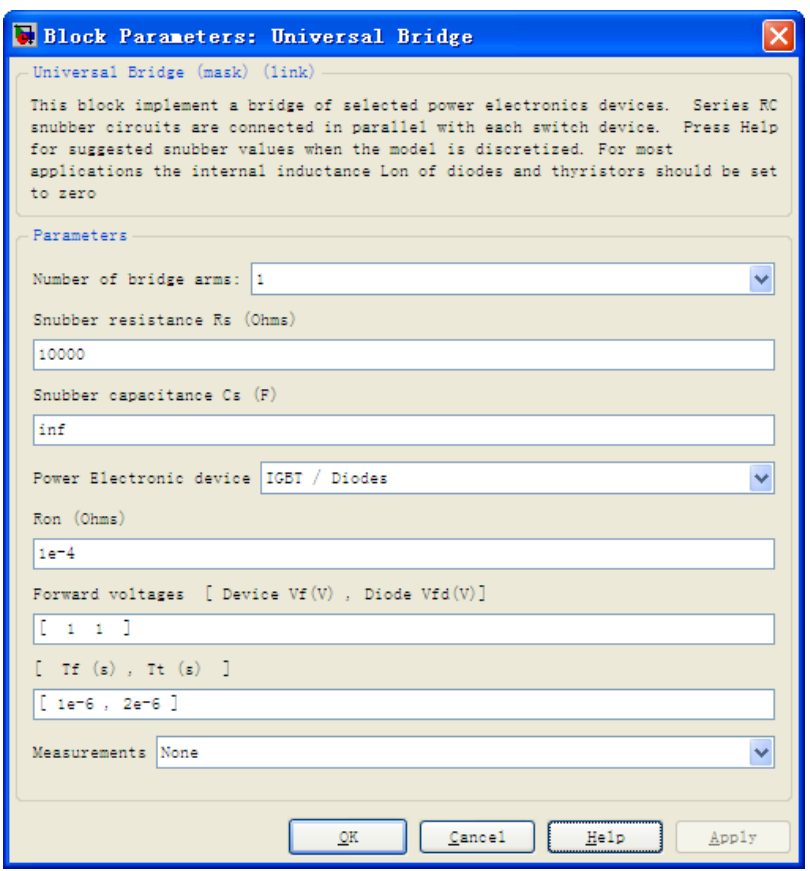

Figure 4. Parameter Settings of Inverter Module 


\section{POWER SUPPLY and LOAD MODULE}

On account of the bi-polar PWM modulation method, two DC voltage sources are connected in series as input, each of which are set to $200 \mathrm{v}$ and grounded. The load is resistance-inductance that parameters are $\mathrm{R}=1 \Omega$ and $\mathrm{L}=5 \mathrm{mH}$.

\section{SimUlation Results}

The simulation algorithm is ode $45 \mathrm{~s}$ and the simulation time is $0-0.05 \mathrm{~s}$. Other parameters are the default values. The output waveform of the load voltage and current is obtained after running the simulation model (see Fig. 5).

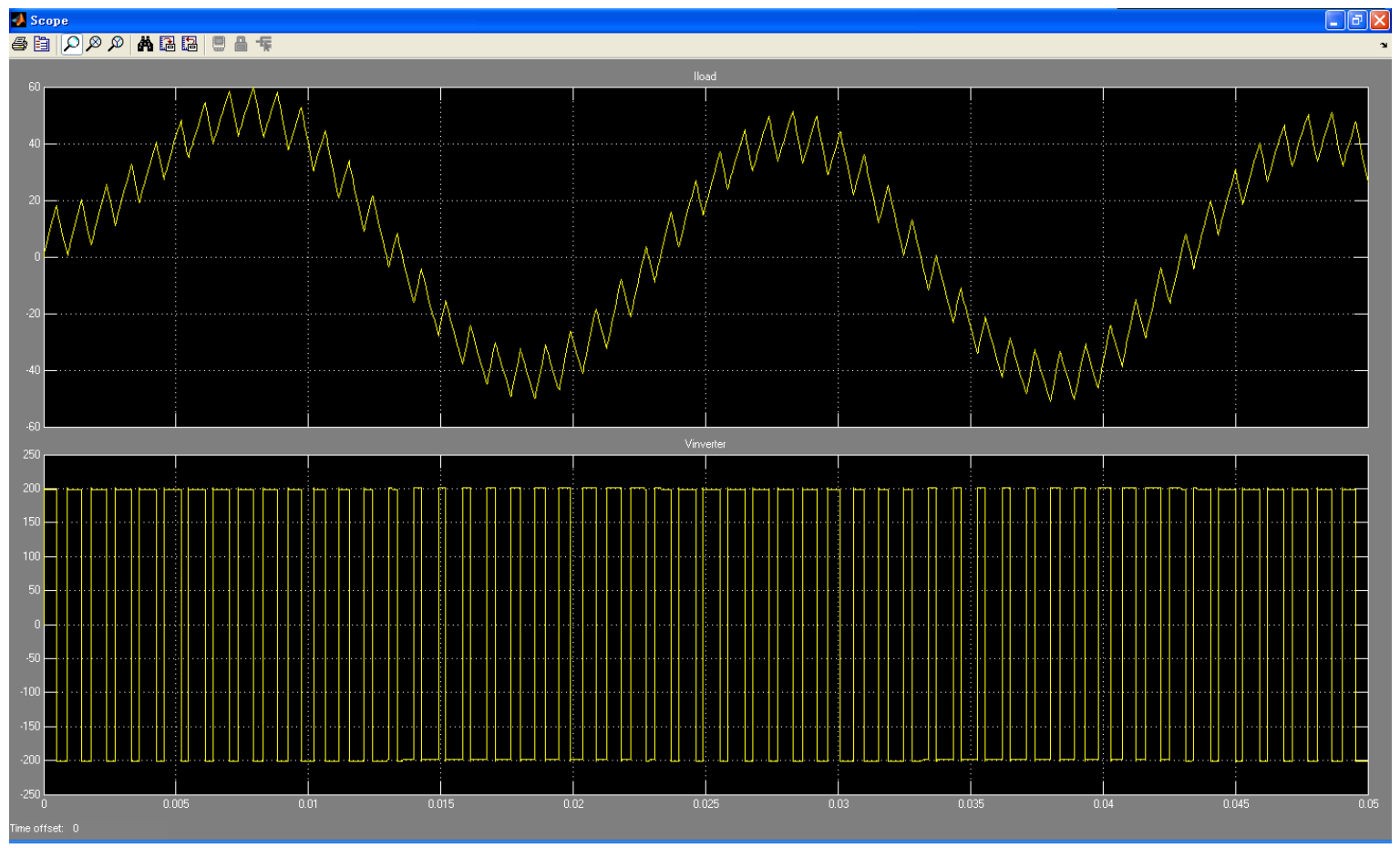

Figure 5. Output Waveform of the Load Voltage and Current

In past teaching processes, it is often appeared that the output waveform is different from the one proposed in the reference book. Because of the packaging devices, students cannot directly confirm the cause like the broken device or incorrect connection, and it will waste a lot of time to replace new devices or line again. This situation hinders the improvement of students' abilities to analyze and solve the problem, and the exercise value of the experimental lessens is weakened. However, MATLAB simulation teaching mode can solve this problem well. It is easy for students to identify the causes of the problems and find out the solutions by establishing the model and adjusting parameters.

\section{TEACHING EFFECT COMPARISON}

In order to test the teaching effect of teaching method, the contrast experiments are researched. Undergraduate students of 2012 grade and 2013 grade are selected as test objects. Common teaching method is applied to undergraduate students of 2012 grade, the teaching method adopted MATLAB simulation is applied to undergraduate students of 2013 grade. Fig. 6 shows the teaching effect of two teaching mode. It can be seen from Fig. 6, the correct rate of undergraduate students of 2012 grade is $57.62 \%$ and the correct rate of undergraduate students of 2013 grade is $81.88 \%$.

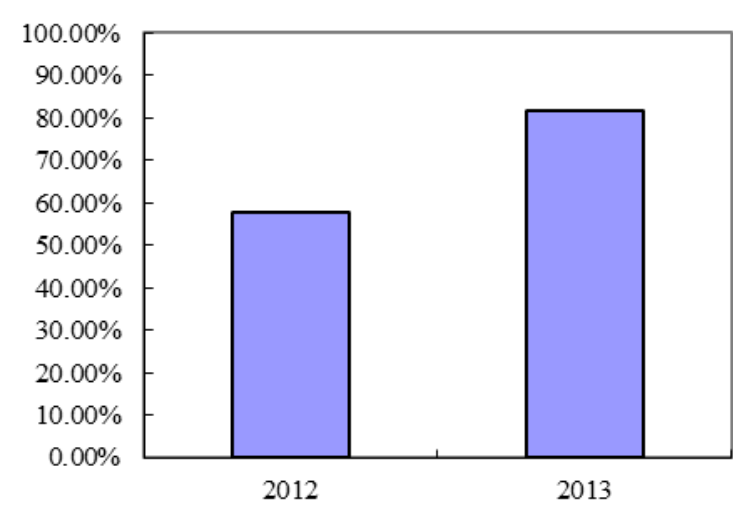

Figure 6. Teaching Effect Comparsion of Two Teching Modes

\section{CONCLUSIONS}

In this paper, taking PWM inverse circuit as an example, an effective teaching mode combining MATLAB and Power Electronic Technology is proposed to show students the working theory and process of the PWM inverse circuit. The comparative experiment of teaching mode combining MATLAB and Power Electronic Technology is proposed to show students the working theory and process of the PWM inverse circuit. The comparative experiment of teaching effect indicates that students are more interested in 
learning and accepting the knowledge in simulation teaching mode, while their ability to analyze and solute problems is strengthened. It is found that after the introduction of MATLAB simulation teaching, the limit of experiment equipment in traditional teaching mode is avoided. Students can analyze the working process of the circuit and observe the possible output waveform by MATLAB, then, build the actual circuit by using experiment devices. In this mode, the learning efficiency is improved obviously and meanwhile the damage rate of experiment device is reduced. Therefore, the MATLAB simulation teaching mode can be used widely in Power Electronic Technology course.

\section{ACKNOWLEDGMENT}

This research is supported by the third phase of construction project of high level graduate curriculum system and graduate core course from Jilin University of China under Grant 2014XH13.

\section{REFERENCES}

[1] Steigerwald R L, "Power electronic converter technology," Proceedings of the IEEE, issue 89, vol 6, 2001, pp. 890-897.

[2] Huang jun, Wang Zhaoan, "Power Electronics Converter Technology (The Fifth Edition)," China Machine Press, 1999.

[3] Erickson R W, Maksimovic D, "Fundamentals of power electronics," Springer Science \& Business Media, 2007.

[4] Chattopadhyay, A.K., "Power electronic converter technology: a State-of-the-Art review," Journal of the
Institution of Engineers (India): Electrical Engineering Division, issue 2-3, vol. 70, 1989, pp. 33-45 .

[5] Bose B, "Global energy scenario and impact of power electronics in 21st century," IEEE Transactions on Industrial Electronics, issue 60, vol 7, 2013, pp. 26382651.

[6] Blaabjerg F, Ma K, "Future on power electronics for wind turbine systems," Emerging and Selected Topics in IEEE Journal of Power Electronics, issue 1, vol 3, 2013, pp. 139-152.

[7] Kim, Yoon-Ho., Kim, Seong-Je., "Prediction of 2-level PWM inverter efficiency using MATLAB/Simulink," International Journal of Electronics, issue 10, vol 102, 2015, pp.1735-1753.

[8] Altintas, Ahmet., "A GUI-based education toolbox for power electronics converters using MATLAB/Simulink and SimPowerSystems," International Journal of Electrical Engineering Education, issue 1, vol. 48, 2011, pp. 53-65.

[9] Ramirez-Cortes, Juan Manuel, "Interactive educational tool for compensators design in MATLAB using frequency response analysis," Computer Applications in Engineering Education, issue 4, vol. 22, 2014, pp. 699707.

[10] Zobaa A. F., Boghdady, T. A, “ Integration into undergraduate courses of transformer tests using MATLAB/Simulink," International Journal of Electrical Engineering Education, issue 4, vol 44, 2007, pp. 319332.

[11] Niculescu Elena, Iancu E.P., Niculescu M.C., Purcaru Dorina-Mioara, "Analysis of PWM converters using MATLAB," WSEAS Transactions on Circuits and Systems, issue 10, vol. 5, 2006, pp. 1522-1527. 